\title{
ANALISIS KESENJANGAN PELAYANAN PADA PASIEN POLIKLINIK RAWAT JALAN MENGGUNAKAN CUSTOMER WINDOW
}

\author{
ANALYSIS OF SERVICE GAPS IN OUTPATIENT POLYCLINIC USING CUSTOMER WINDOW \\ Linta Meyla Putri, Stefanus Supriyanto \\ Fakultas Kesehatan Masyarakat, Universitas Airlangga, Surabaya \\ Email: lintameyla@gmail.com
}

\begin{abstract}
Patient complaints toward service at Undaan Eyes Hospital in 2015 amounted to 9 complaints, and has not yet reached target set by the hospital which was equal to 0 complaints. Therefore, the purpose of this research is to analyze gaps in expected service and perceived service of responsiveness, reliability and emphatyat UndaanEyes Hospital. This research was an analytic observational survey and to be analyzed by customer window. Sample were in equal to 98 people and collected by systematic random sampling. The result showed from the analysis of the customer windowwas that some aspects in service are in quadrant A or Attention, which patient expected service higher than perceived service. Some aspects that were in Attention quadrant, are: waiting time > 30 minutes, speed of service delivery was slow and lack information. It can be concluded that some of the things that are in quadrant $A$ or Attention is a strategic issue that must consider and resolve byUndaan Eyes Hospital to meet the expectations of patients.
\end{abstract}

Keywords: customer window, gap analysis, service

\section{PENDAHULUAN}

Perkembangan bidang kesehatan pada saat ini banyak mengalami perubahan dan kemajuan, termasuk di Indonesia, salah satunya adalah bidang perumahsakitan. Rumah sakit merupakan unit pelaksana pelayanan kesehatan yang integratif dan komprehensip, yang mempunyai peran cukup besar untuk meningkatkan derajat kesehatan. Perkembangan dunia perumahsakitan yang pesat di Indonesia mendorong terjadinya persaingan dalam produk layanan kesehatan. Rumah sakit sebagai industri jasa memerlukan manajemen untuk mengelola sumberdaya yang dimiliki. Untuk menghadapi ketatnya persaingan dalam menyediakan produk layanan kesehatan yang berkualitas bagi masyarakat selaku konsumen, tentunya rumah sakit tidak bisa lepas dari aspek pemasaran agar mampu memuasakan kebutuhan dan harapan pasien. Rumah sakit juga harus bisa memanfaatkan setiap sumberdaya yang ada untuk mencapai tujuan pelayanan yang berkualitas serta dapat meminimalisir datangnya keluhan dari pasien terhadap pelayanan yang diberikan oleh rumah sakit.

Rumah Sakit Mata Undaan adalah rumah sakit swasta milik Perhimpunan Perawatan Penderita Penyakit Mata (P4M). RS Mata Undaan merupakan salah satu fasilitas pelayanan kesehatan perorangan yang memberikan pelayanan kesehatan mata secara menyeluruh dalam mendukung penyelenggaraan upaya kesehatan. Hasil survei Morbiditas Mata dan Kebutaan di Indonesia yang dilaksanakan oleh Kementerian Kesehatan RI bekerjasama dengan Perhimpunan Dokter Ahli Mata Indonesia gangguan penglihatan dan kebutaan masih menjadi masalah kesehatan di Indonesia. Survei Kesehatan Indera tahun 2009-2014 menunjukkan $1,5 \%$ penduduk Indonesia mengalami kebutaan disebabkan oleh katarak $(52 \%)$, glaukoma $(13,4 \%)$, kelainan refraksi $(9,5 \%)$, gangguan retina $(8,5 \%)$, kelainan kornea $(8,4 \%)$ dan penyakit mata lain. 
Tingginya gangguan penyakit mata tentu berdampak pada peningkatan jumlah pasien layanan kesehatan mata, termasuk di RS Mata Undaan. Visi RS Mata Undaan adalah menjadi pilihan utama masyarakat dalam pelayanan kesehatan mata. Salah satu misinya yaitu memberikan pelayanan kesehatan mata bermutu tinggi dan terjangkau. Bermutu dan terjangkau artinya dalam memberikan pelayanan kesehatan mata yang melebihi harapan pasien.

\section{Berdasarkan Arsip Komplain RS Mata}

Undaan dari tahun 2012 hingga tahun 2015 ditemukan beberapa keluhan dengan permasalahan yang sama dan terjadi berulang. Seperti keluhan pasien tentang pelayanan yang lama, pelayanan administrasi yang kurang tertib, serta ketidakramahan petugas. Selain itu terdapat juga ketidakjelasan alur antara pasien rumah sakit dengan pasien pribadi dokter, dan jadwal dokter yang padat juga dapat menimbulkan keluhan pasien.

Marketing mixdi rumah sakit merupakan strategi dalam melaksanakan kegiatan marketing secara maksimal sehingga menghasilkan kepuasan bagi pasien. Salah satu unsur marketing mix adalah process atau service. Perlu dilakukan pemantauan dan evaluasi terhadap pelaksanaan service di rumah sakit berdasarkan harapan dan persepsi pasien. Dibutuhkan komitmen yang kuat dari pihak manajemen untuk mempertahankan pelanggan agar dapat terus bertahan dan tidak tenggelam dalam persaingan. Menurut Lovelock dan Wirtz (2007) kepuasan pelanggan adalah perasaan senang atau kecewa yang didapatkan seseorang dari membandingkan antara kinerja (atau hasil) produk yang dipersepsikan dengan ekspektasinya.
Berdasarkan Arsip Komplain RS Mata Undaanpada tahun 2015 ketidakpuasan terhadap faktor service disebabkan karena perbedaan layanan yang diharapkan dan pelayanan yang diterima oleh pasien terkait aspek kecepatan pelayanan, sikap petugas dan waktu tunggu. Penelitian ini bertujuan untuk mengidentifikasi Expected Service dan Perceived Service, kemudian menganalisis kesenjanganuntuk mengetahui perbedaan antara pelayanan yang diharapkan dengan pelayanan yang diterima oleh pasien yang berdampak pada kepuasan pasien dengan menggunakan Customer Window. Penelitian ini diharapkan dapat bermanfaat sebagai bahan evaluasi proses manajemen dalam upaya peningkatan kepuasan pasien di RS Mata Undaan Surabaya.

\section{PUSTAKA}

Menurut Zeithmal et.al (2000) perceived service adalah persepsi pelanggan terhadap pelayanan yang diterima. Apabila persepsi terhadap pelayanan sesuai dengan yang diharapkan pelanggan, maka kualitas layanan dipersepsikan sebagai kualitas yang ideal.Sebaliknya apabila persepsi terhadap layanan lebih jelek dibandingkan dengan yang diharapkan pelanggan, maka kualitas pelayanan dipersepsikan negatif atau buruk.

Harapan pelanggan diyakini memegang peran besar dalam penentuan kualitas produk (barang dan jasa) dan kepuasan konsumen. Pada dasarnya ada hubungan erat antara penentuan kualitas dan kepuasan pelanggan. Pelangggan menggunakan harapannya sebagai acuan atau satandar dalam mengevaluasi kualitas suatu produk. 
Selain sebagi standar prediksi, ada pula yang memakai harapan sebagai standar ideal (Tjiptono, 2005).

Kepuasan didefinisikan sebagai tingkat perasaan seseorang setelah membandingkan kinerja atau hasil yang dirasakan dengan harapan (Kotler, 2009). Agar dapat memuaskan pelanggan maka harus diidentifikasi dahulu apa keinginan, kebutuhan dan harapan pelanggan sehingga pengorbanan yang telah dikeluarkan pelanggan sebanding yang didapatkan bahkan lebih. Menurut Zeithmal et., al (2000) kualitas pelayanan adalah perbedaan antara harapan pelanggan dan kinerja layanan yang dirasakan. Pelayanan di Rumah Sakit merupakan hubungan interaksi antara pemberi pelayanan dengan pelanggan. Proses interaksi ini bisa dijadikan indikator baik tidaknya mutu pelayanan jasa. Pelayanan merupakan semua aktivitas pekerjaan yang meliputi pemberian pelayanan berupa prosedur, mekanisme, kecepatan, ketepatan dan keramahan (Supriyanto \& Ernawaty, 2010). Hal merupakan salah satu kunci untuk meningkatkan mutu pelayanan agar timbul kepuasan dan tidak terjadi keluhan pelanggan.

Menurut Gasperz (2005)dalam memahami ekspektasi pelanggan dapat menggunakan suatu alat yang disebut Customer Window. Alat ini diperkenalkan oleh ARBOR Inc, suatu perusahaan riset pasar dan TQM yang berpusat di Philadelphia. Customer window adalah salah satu alat analisis kesenjangan untuk memahami kepuasan dan kepentingan relatif (ururtan kepentingan) pelanggan terhadap karakteristik produk atau jasa yang dikonsumsinya (Supriyanto dan Ernawaty, 2010).

\begin{tabular}{|c|c|}
\hline $\begin{array}{c}\text { ATTENTION } \\
\text { Diharapkan \& pelanggan } \\
\text { Tidak Puas }\end{array}$ & $\begin{array}{c}\text { BRAVO } \\
\text { Diharapkan \& } \\
\text { pelanggan } \\
\text { Puas }\end{array}$ \\
\hline DONT WORRY BE & $\begin{array}{c}\text { CUT or } \\
\text { HAPPY }\end{array}$ \\
$\begin{array}{c}\text { COMMUNICATION } \\
\text { Tidak diharapkan \& } \\
\text { pelanggan } \\
\text { Tidak Puas }\end{array}$ & $\begin{array}{c}\text { \& pelangan } \\
\text { Puas }\end{array}$ \\
\hline
\end{tabular}

Gambar 1.Customer window (Gaspersz, 2005)

Kuadran attention yaitu pelanggan menginginkan karakteristik tersebut tetapi tidak mendapatkannya. Pada situasi di rumah sakit pelayanan ini diinginkan oleh pasien, namun pasien tidak memperolehnya. Pada area ini pasien merasa tidak puas. Strategi yang dapat dilakukan adalah tingkatkan kinerja pelayanan untuk memenuhi harapan pasien.

Kuadran bravo yaitupelanggan menginginkan karakteristik tersebut dan mendapatkannya. Pada situasi di rumah sakit pelayanan ini diinginkan oleh pasien, dan pasien memperolehnya. Pada area ini pasien merasa puas. Strategi yang dapat dilakukan adalah mempertahankan kinerja pelayanan sesuai dengan harapan pasien.

Kuadran cut or comunication yaitu pelanggan tidak menginginkan karakteristik tersebutnamun pelangganmendapatkannya. Pada situasi rumah sakitpelayanan tersebut tidak diinginkan oleh pasien, namun pasien memperolehnya. Rumah sakit harus mengetahui apa alasan pasien tidak mengharapkan hal tersebut. Strategi yang dapat dilakukan adalah memberikan prioritas rendah pada pelayanan tersebut atau mempromosikan betapa pentingnya pelayanan tersebut bagi pasien. 
Kuadran don't worry be happy yaitupelanggan tidak menginginkan karakteristik tersebut, danpasien juga tidak mendapatkannya. Pada situasi ini di rumah sakit pelayanan tidak diinginkan pasien dan rumah sakit tidak perlu menyediakan. Strategi yang dapat dilakukan adalahmempertimbangkan untuk meniadakan pelayanan tersebut.

Customer Gap merupakan bagian dari quality gap yang disebabkan adanya perbedaan antara pelayanan yang diharapkan (Expected Service) dan pelayanan yang dirasakan (Perceived Service) oleh pelanggan. Customer gap ini merupakan suatu adaptasi model persepsi dan harapan pelanggan tehadap kualitas pelayanan jasa yang dikembangkan oleh Zeithmal et., al (2000) yang bernama Customer Experience Gap Model.

\section{METODE}

Penelitian ini adalah penelitian observasional analitik untuk menganalisis penilaian pada pelayanan yang diterima dan harapan pelanggan terkait pelayanan poliklinik rawat jalan dengan menggunakan Customer Window di RS Mata Undaan. Penelitian ini menggunakan rancang bangun cross sectional.

Populasi dalam penelitian ini adalah pasien umum poliklinik rawat jalan RS Mata Undaan Surabaya pada bulan April 2016 sebanyak 3566 kunjungan.

Besar sampel penelitian ini adalah 98 orang yang dipilih menggunakan teknik systematic random sampling $(\alpha=0,05)$. Pengambilan data dilakukan dengan kuesioner untuk menilai kualitas pelayanan (service quality)terhadap aspek responsiveness, reliability dan emphaty antara pelayanan yang diharapkan dan pelayanan yang diterima pasien pada pelayanan poliklinik rawat jalan RS Mata Undaan Surabaya.

Masing-masing atribut pertanyaan dalam kuisioner dihitung nilai dan mean-nya, lalu dihitung pula nilai mean komposit. Nilai mean komposit akan digunakan sebagai nilai batas (cut off point). Bila nilai atribut harapan diatas nilai mean komposit, harapan akan diletakkan dalam kuadran yang berada diatas batas sesuai absis grafik, sedangkan nilai atribut penilaian yang berada di atas nilai mean komposit penilaian diletakkan dalam kuadran di kanan nilai batas sesuai ordinat grafik. Garis dari kedua mean komposit akan membagi matriks menjadi 4 kuadran. Kuadran tersebut antara lain kuadran Attention, Bravo, Cut or Communication dan Dont WorryBe Happy.

Berdasarkan data penilaian terhadap pelayanan yang diterima dan pelayanan yang diharapkan pasien terdapat nilai masing-masing variabel yang akan menjadi koordinat $X$ dan $Y$ dalam customer window. Selanjutnya dari kedua koordinat nilai $X$ dan $Y$ dapat dilihat posisi masing-masing variabel yang diteliti berada pada kuadran yang berbeda.

Varibel yang berada pada kuadran $A$ atau Attention harus menjadi prioritas utama untuk diperhatikan dan diselesaikan guna memenuhi harapan pelanggan. Analisis danpembahasan akan difokuskan pada aspek yang berada pada kuadran Attention. 


\section{HASIL DAN PEMBAHASAN}

Rumah Sakit Mata Undaan merupakan rumah sakit khusus tipe B yang melaksanakan pengobatan mata secara paripurna. Poliklinik Rawat Jalan RS Mata Undaan melayani pasien kategori umum dan BPJS. Pelayanan dilakukan dalam gedung yang sama, mulai dari pendaftaran, pemeriksaan refraksi dan pemeriksaan dokter.
Kesenjangan Expected Service dan Perceived Service pasien.

Penghitungan expected service dan
perceived service dilakukan dengan cara
membandingkan kedua aspek tersebut berdasarkan unsur responsiveness, reliability dan emphaty. Hasil penghitungan nilai perceived service pasien di poliklinik rawat jalan RS Mata Undaan pada pada Tabel 2.

Tabel 2 Perceived ServicePasien Terhadap Unsur Pelayanan di Poliklinik Rawat Jalan RS Mata Undaan Tahun 2016

\begin{tabular}{lcc}
\hline \multicolumn{1}{c}{ Aspek } & Total & Mean \\
\cline { 2 - 3 } $\begin{array}{l}\text { Responsiveness } \\
\text { Kecepatan pemberian pelayanan }\end{array}$ & 2,65 \\
Waktu tunggu < 30 menit & 260 & 2,09 \\
Kemudahan hubungan dengan petugas & 205 & 2,84 \\
Reliability & 279 & 2,63 \\
Kejelasan informasi & & 3,07 \\
Pelayanan yang teliti dan hati-hati & 258 & 2,95 \\
Emphaty & 301 & 2,96 \\
Penjelasan tentang penyakit dan rencana terapi & 290 & 2,74 \\
Kepedulian petugas untuk membantu & 291 & \\
\hline \multicolumn{2}{c}{ Mean Komposit } \\
\hline
\end{tabular}

Pada aspek responsiveness hal yang diteliti yaitu kecepatan dalam pemberian pelayanan, waktu tunggu, dan kemudahan hubungan dengan petugas Selanjutnya untuk aspek reliability hal yang diteliti yaitu kejelasan informasi tentang pelayanan di rumah sakit serta ketelitian dan kehati-hatian pelayanan yang diberikan petugas. Kemudian untuk aspek emphaty hal yang diteli yaitu penjelasan tentang penyakit dan rencana terapi serta kepedulian petugas untuk membantu pasien. Berdasarkan Tabel 2 dapat diketahui bahwa bahwa mean penilaian tertinggi adalah aspek pelayanan yang teliti dan hatihati sebesar 3,07 . Nilai mean tersebut menunjukkan bahwa pasien merasa sangat mendapatkan pelayanan yang teliti dan hati-hati dari petugas.
Pelayanan yang teliti dan hati-hati menunjukkkan kehandalan atau reliabilitas dari sebuah RS. Hal ini sesuai dengan pendapat Amriyati (2003) menyatakan bahwa pelayanan yang teliti dan hati-hati merupakan salah satu indikator reliability sebuah pelayanan kesehatan. Mean penilaian terendah adalah aspek waktu tunggu yang cukup lama yaitu sebesar 2,09. Hal ini menunjukkan bahwa waktu tunggu untuk mendapatkan pelayanan di poliklinikrawat jalan RS Mata Undaan cukup lama dan lebih dari 30 menit. Salah satu penyebabnya adalah pelayanan terhadap pasien BPJS dan pasien umum yang tidak dipisah, sehingga menimbulkan padatnya antrian dan lamanya waktu tunggu. Waktu tunggu yang lama dapat memicu ketidakpuasan pasien terhadap pelayanan. 
Tabel 3 Expected Service Pasien Terhadap Unsur Pelayanan di PoliklinikRawat Jalan RS Mata Undaan Tahun 2016

\begin{tabular}{|c|c|c|}
\hline \multirow{2}{*}{ Aspek } & \multicolumn{2}{|c|}{ Total } \\
\hline & $\Sigma$ Skor & Mean \\
\hline \multicolumn{3}{|l|}{ Responsiveness } \\
\hline Kecepatan pemberian pelayanan & 373 & 3,85 \\
\hline Waktu tunggu $<30$ menit & 370 & 3,77 \\
\hline Kemudahan hubungan dengan petugas & 327 & 3,33 \\
\hline \multicolumn{3}{|l|}{ Reliability } \\
\hline Kejelasan informasi & 355 & 3,62 \\
\hline Pelayanan yang teliti dan hati-hati & 368 & 3,75 \\
\hline \multicolumn{3}{|l|}{ Emphaty } \\
\hline Penjelasan tentang penyakit dan rencana terapi & 339 & 3,45 \\
\hline Kepedulian petugas untuk membantu & 328 & 3,34 \\
\hline Mean Komposit & & 3,58 \\
\hline
\end{tabular}

Pada Tabel 2 dapat diketahui mean komposit untuk perceived service adalah sebesar 2,74. Nilai mean komposit pelayanan yang diterima akan menjadi cut off point pada ordinat customer window. Selanjutnya berdasarkan Tabel 3 dapat diketahui bahwa mean harapan tertinggi dimiliki oleh aspek harapan terhadap kecepatan pemberian pelayanan yaitu 3,85. Hal ini menunjukkan bahwa aspek kecepatan pemberian pelayanan merupakan hal yang sangat diharapkan oleh pasien. Kondisi psikologis pasien yang sedang sakit menuntut adanya respon yang cepat dari pihak rumah sakit untuk segera menangani keluhannya. Aspek responsiveness untuk memberikan pelayanan yang cepat atau responsif merupakan salah satu hal yang mempengaruhi kepuasan pasien terhadap pelayanan.

Tabel 4. Nilai koordinat variabel pelayanan
Mean harapan terendah adalah nilai terhadap kemudahan hubungan dengan petugas, yaitu 3,34. Menunjukkan bahwa pasien tidak begitu mengharapkan aspek kemudahan hubungan dengan petugas.Pasien tidak begitu mengharapkan hal tersebut karena petugas jaga sudah cukup mudah untuk dihubungi ketika pasien merasa kurang jelas dengan proses dan prosedur pelayanan.

Mean komposit untuk expected serviceadalah sebesar 3,58. Nilai mean komposit harapan akan menjadi cut off point pada absis customer window. Nilai meanexpected service dan perceived service dari setiap variabel kemudian menjadi titik koordinat untuk menentukan posisi variabel dalam customer window.

\begin{tabular}{lc}
\hline \multicolumn{1}{c}{ Variabel } & Nilai Koordinat(X; $\mathbf{Y})$ \\
\hline Responsiveness & 2,$65 ; 3,85$ \\
Kecepatan pemberian pelayanan & 2,$09 ; 3,77$ \\
Waktu tunggu < 30 menit & 2,$84 ; 3,33$ \\
Kemudahan hubungan dengan petugas & \\
Reliability & 2,$65 ; 3,84$ \\
Kejelasan informasi & 3,$07 ; 3,75$ \\
Pelayanan yang teliti dan hati-hati & \\
Emphaty & 2,$97 ; 3,45$ \\
Penjelasan tentang penyakit dan rencana terapi & 2,$96 ; 3,34$ \\
\hline
\end{tabular}




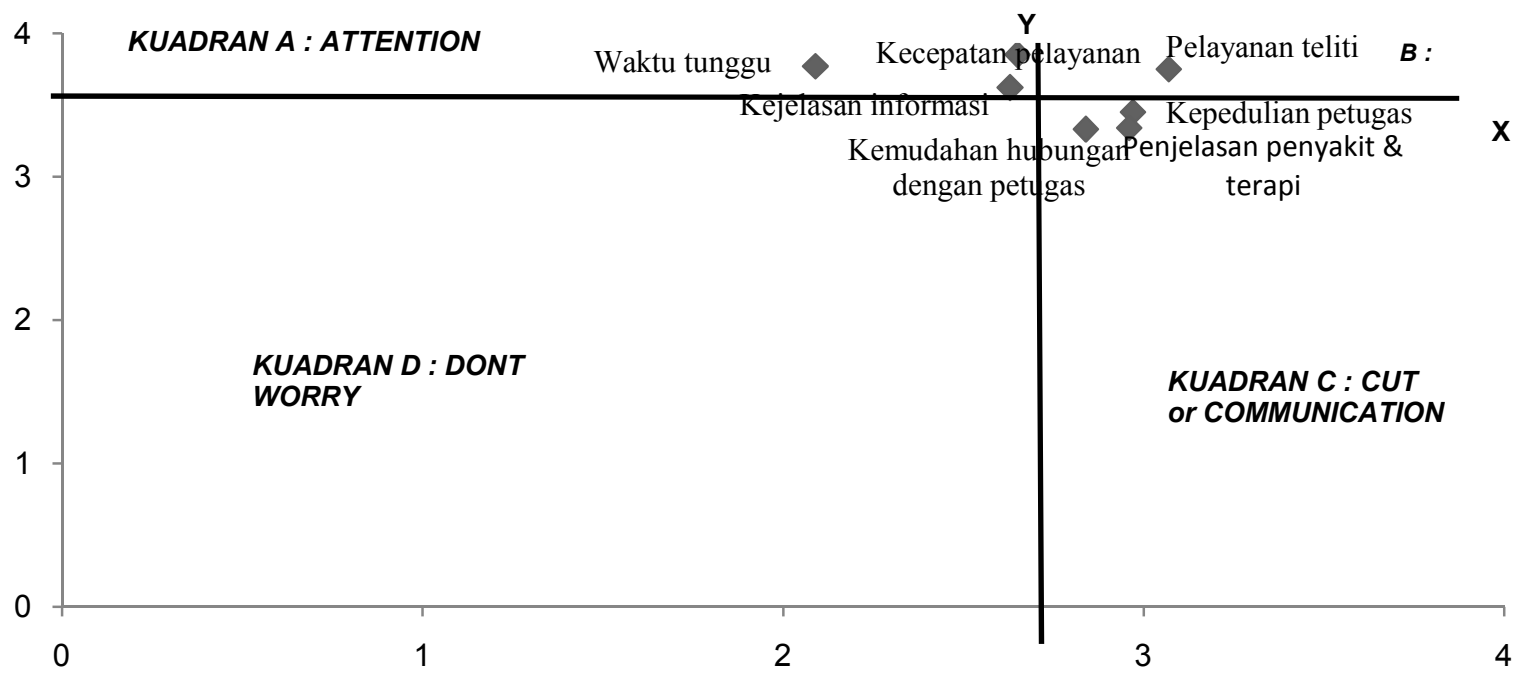

Gambar 2 Customer WindowExpected Service dan Perceived Service Pasien di Poliklinik Rawat Jalan RS Mata Undaan

Berdasarkan Gambar 2 terdapat 3 hal yang berada pada kuadran Attention yaitu: kecepatan pemberian pelayanan, waktu tunggu yang lebih dari 30 menitdan kejelasan infromasi. Selanjutnya pelayanan yang teliti dan hati-hati berada pada kuadran Bravo. Kemudian terdapat 3 hal yang berada pada kuadran Cut or Communication yaitu: penjelasan tentang penyakit \& pengobatan, kemudahan hubungan dengan petugas dan kepedulian petugas. Selanjutnya tidak terdapat aspek yang berada pada kuadranDont Worry Be Happy.

Berdasarkan hasil analisis customer window terhadap unsur pelayanan di Poliklinik Rawat Jalan RS Mata Undaan, ada tiga aspek yang berada pada kuadran Attention. Aspek yang berada pada kuadranAttentionmerupakan isu strategis dan difokuskan untuk dibahas serta diselesaikan. Sesuai dengan pendapat Yanuaria dan Wulandari (2013) bahwa isu strategis dari voice of customer merupakan salah satu hal yang harus diperhatikan

Analisis customer gap antara penilaian dan harapan pasien tentang unsur kecepatan pelayanan , waktu tunggu pelayanan lebih dari 30 menit, dan kejelasan informasi berada pada kuadran $\mathrm{A}$ atau Attention. Menunjukkan bahwa ketiga hal tersebut merupakan aspek yang sangat harapkan oleh pasien namun pasien merasa tidak mendapatkannya sehingga dapat memicu ketidakpuasan.

Aspek kecepatan pemberian pelayanan berada pada kuadran Attention yang menunjukkan bahwa pasien sebenarnya sangat mengharapkan pemberian pelayanan yang cepat namun pasien merasa tidak memperolehnya. Pasien di Poliklinik RS Mata Undaan harus melewati beberapa tahap pemeriksaan yaitu pemeriksaan awal poli 1 yang meliputi pemeriksaan Automatic Refrakto Keratometer (ARK), Non-Contact Tonometri (NCT) maupun refraksi. Kemudian dilanjutkan dengan 
pemeriksaan di Poli 2 dan 3 yaitu pemeriksaan oleh dokter spesialis mata dan dilanjutkan ke Poli 4 untuk dilakukan edukasi. Petugas mengulang kembali apa yang dijelaskan oleh dokter pemeriksa mengenai tindakan yang direncanakan. Pasien diberikan kebebasan untuk berfikir dan mengambil keputusan. Pasien merasa sangat lama ketika melakukan pemeriksaan di poli 1, hal ini dikarenakan pemeriksaan untuk pasien BPJS dan pasien Umum dicampur menjadi satu sehingga menyebabkan ruangan yang kurang kondusif dan waktu pemeriksaan yang cukup lama. Waktu pemeriksaan yang lama juga disebabkan karena terkadang jumlah dokter jaga di poliklinik rawat jalan memiliki jumlah yang tidak sesuai Standar Pedoman Rawat Jalan RS Mata Undaan, yakni 7 orang dokter pemberi pelayanan medis rawat jalan. Terkadang beberapa dokter memiliki jadwal operasi yang bertabrakan dengan jadwal jaga sehingga poliklinik rawat jalan kekurangan dokter jaga. Menurut Utama (2013) kecepatan pemberian pelayanan merupakan salah satu bentuk responsif dari dokter sehingga ketepatan jumlah dokter merupakan hal yang sangat berpengaruh dalam menunjang aspek responsiveness.

Aspek waktu tungguberada pada kuadran Attention, hal ini menunjukkan bahwa pasien sangat mengharapkan waktu tunggu yang kurang dari 30 menit, namun pasien tidak mendapatkannya. Lamanya waktu tunggu terhadap pelayanan dapat memicu ketidakpuasan pelanggan terhadap unsur pelayanan.Hal ini menunjukkan rendahnya aspek responsiveness di RS Mata Undaan. Salah satu penyebabnya adalah pelayanan terhadap pasien
BPJS dan pasien umum tidak dipisah, sehingga menimbulkan padatnya antrian dan lamanya waktu tunggu. Waktu tunggu yang lama dapat memicu ketidakpuasan pasien terhadap pelayanan. Sesuai pendapat dari Utami (2012) bahwa waktu tunggu identik denfan kecemasan dan kejenuhan sehingga beresiko menurunkan kepuasan pasien.

Menurut Kemenkes Nomor 129/Menkes/SK/II/2008 tentang Standar Pelayanan Minimal Rumah Sakit, bahwa waktu tunggu untuk rawat jalan ialah kurang dari 60 menit, jika lebih dari 60 menit pelayanan rawat jalan tersebut bisa dikatakan tidak sesuai standar. Waktu tunggu pelayanan yang cepat merupakan hal yang diinginkan oleh pasien, sehingga sebaiknya rumah sakit memperhatikan lamanya waktu tunggu pelayanan oleh pasien, karena waktu tunggu yang semakin cepat akan meningkatkan kepuasan pasien terhadap kinerja pelayanan (Putri, 2016).

Aspek kejelasan informasi juga berada pada kuadran Attention, menunjukkan bahwa pasien mengharapkan informasi yang jelas ketika berobat di RS Mata Undaan, namun pasien tidak mendapatkannya. Informasi yang disampaikan melalui alat pengeras suara kadang tidak terdengar jelas oleh pasien, sehingga ketika nama pasien dipanggil untuk pemeriksaan seringkali pasien tidak mendengar. Kondisi ruang tunggu yang cukup ramai dan keterbatasan kualitas alat pengeras suara juga menyebabkan ketidakjelasan informasi yang diterima pasien dan dapat memicu ketidakpuasan pasien pada pelayanan di RS Mata Undaan Surabaya. Kualitas aspek communication dan tangible di RS Mata Undaan kurang memenui harapan pasien. 
Menurut Supriyanto dan Ernawaty (2010) salah satu unsur tangible adalah bahan komunikasi menunjang jasa yang ditawarkan agar memudahkan komunikasi dan penyampaian pesan untuk pasien.

\section{SIMPULAN}

Hasil analisis customer window di poliklinik rawat jalan RS Mata Undaan Surabaya menunjukkan bahwa aspek kecepatan pelayanan, waktu tunggu dan kejelasan informasi berada pada kuadran Attention. Artinya hal tersebut sangat diharapkan pasien namun pasien tidak mendapatkannya. Aspek tersebut menjadi isu strategis bagi pihak manajemen rumah sakit, sehingga harus menjadi perhatian dan prioritas untuk diselesaikan.

Peningkatan kecepatan pemberian pelayanan dengan memastikan jumlah dokter jaga di Poliklinik Rawat Jalan RS Mata Undaan penuh sebanyak 7 dokter pelaksana pelayanan medis rawat jalan sesuai Standar Pedoman Rawat Jalan RS Mata Undaan.Perbaikan waktu tunggu dapat dilakukan dengan melakukan pemisahan pelayanan pasien BPJS dan pasien umum mulai dari proses pendaftaran hingga pemeriksaan.Perbaikan kejelasan pemberian informasi melalui alat pengeras suara di ruang tunggu dengan mengatur agar proses pemanggilan pasien tidak bersahut-sahutan, dan pengarahan agar pasien berada di dekat poli pemeriksaan yang akan dituju.

\section{DAFTAR PUSTAKA}

Amriyati. (2003). Kinerja Perawat Ditinjau dari Lingkungan Kerja dan Karakteristik Individu. Jurnal Manajemen Pelayanan Kesehatan. Vol 6 No 1.
Gaspersz, V. 2005. Total Quality Management. Jakarta: Gramedia Pustaka Utama.

Lovelock, C and Wirtz, J. (2007). Service Marketing. Fifth Edition,Prentice Hall, New Jersey

Kementerian Kesehatan Republik Indonesia. (2014). Survey Morbiditas Mata Tahun 2009-2014. Jakarta.

Kementerian Kesehatan. (2008). Keputusan Menteri Kesehatan Nomor 129 tahun 2008 tentang Standar Pelayanan Minimal Rawat Jalan di Rumah Sakit. Jakarta.

Kotler, Philip. (2009). Manajemen Pemasaran. Edisi Milenium diterjemahkan Benyamin Molan. Jakarta: PT.Prenhallindo.

Putri, Linta Meyla. (2016). Analisis Marketing Mix (People, Process, Place, Physical Facility) Pada Pasien Rawat Jalan Dengan Menggunakan Customer window (Studi Pasien Rawat Jalan Poliklinik Pagi di Rumah Sakit Mata Undaan Surabaya). Skripsi. Universitas Airlangga Surabaya.

RS Mata Undaan Surabaya. (2016). Pedoman Pelaksanaan Rawat Jalan RS Mata Undaan tahun 2016. Surabaya.

RS Mata Undaan Surabaya. (2015). Arsip Komplain RS Mata Undaan. Surabaya.

Supriyanto, S., Ernawaty. (2010). Pemasaran Industri Jasa Kessehatan. Yogyakarta: Penerbit Andi.

Tjiptono, Fandy. (2005). Pemasaran Jasa,Edisi pertama. Malang: Bayu Media Publishing.

Utama, Agung. (2013). Aanalisis Pengaruh Persepsi Kualitas Pelayanan Terhadap Kepuasan Pelanggan RSU Cakra Husada Klaten. Jurnal OPSI. Vol 1 No 2.

Utami, Yeni Tri. (2012). Hubungan Waktu Tunggu Pelayanan Rawat Jalan Dengan Tingkat Kepuasan Pasien Di RSU Assalam Gemolong. Jurnal APIKES Citra Medika. Vol 4 No 9.

Yanuaria, Myrra., \& Wulandari, R.D. (2013). Penyusunan Upaya Peningkatan Pelayanan Antenatal Care berdasarkan Voice of Customer. JurnalAdministrasi Kesehatan Indonesia. Vol 1 No 1. pp 66-74.

Zeithaml, Valerie A., Parasuraman A., \& Berry, Leonard. (2000). Delivering Quality Service: Balancing Customer Perception and Expectation. New York, The Free Press. 